\title{
The perception of color from motion
}

\author{
CAROL M. CICERONE, DONALD D. HOFFMAN, PETER D. GOWDY, and JIN S. KIM \\ University of California, Irvine, California
}

\begin{abstract}
We introduce and explore a color phenomenon which requires the prior perception of motion to produce a spread of color over a region defined by motion. We call this motion-induced spread of color $d y$ namic color spreading. The perception of dynamic color spreading is yoked to the perception of apparent motion: As the ratings of perceived motion increase, the ratings of color spreading increase. The effect is most pronounced if the region defined by motion is near $1^{\circ}$ of visual angle. As the luminance contrast between the region defined by motion and the surround changes, perceived saturation of color spreading changes while perceived hue remains roughly constant. Dynamic color spreading is sometimes, but not always, bounded by a subjective contour. We discuss these findings in terms of interactions between color and motion pathways.
\end{abstract}

Neon color spreading (see, e.g., van Tuijl, 1975; Varin, 1971) shows that the colors we perceive do not always match predictions based on the spectral content of the stimulus. In instances of neon color spreading, color is seen over regions which in isolation would appear achromatic. Specific geometric, color, and brightness features are required in order to induce the neon color spreading into nearby areas. Consider the example in Figure 1: A full green disk can be seen, although only eight radial lines, part green and part red, are drawn. Another feature of the colored disk is that it appears luminous-hence the label "neon" color spreading.

In this paper we introduce and explore a phenomenon of color spreading which differs from standard neon color spreading in that it requires the prior perception of motion to produce a spread of color over a region defined by motion. We call this motion-induced color spreading dynamic color spreading for short. Two frames from a typical display of dynamic color spreading are shown in Figure 2. Each frame consists of a white square containing 900 dots placed randomly (sampled from a uniform distribution) within the square area. The dots do not move from one frame to the next; only their colors are updated as follows: All dots are colored red except for those within a (virtual) disk, which are colored green. The center of the disk translates from one frame to the next, with the consequence that some red dots in one frame are green in the next, and vice versa. Again, the physical placement of dots remains unchanged from frame to frame; only the colors of a small number of dots (those at the leading and trailing edges of the virtual disk) change from one frame to the next. The

We thank M. Albert, B. Bennett, M. Braunstein, J. Yellott, and two anonymous reviewers for helpful comments. This research was supported by ONR Contract N00014-88-K-0354 (D.D.H.), NSF Grant BNS8819874 (C.M.C.), and NEI Grant 1 RO1EY08200 (C.M.C.). Correspondence should be addressed to $C$. M. Cicerone, Department of Cognitive Sciences, University of California, Irvine, Irvine, CA 92717 (e-mail: cciceron@uci.edu).
Mathematica (Version 2.03) program used for generating such frames is given in Appendix A.

When frames, such as those shown in Figure 2, are shown in rapid succession, one sees more than just dots changing color; one sees a moving, luminous region, uniformly colored green, that is bounded by a circular subjective contour. (Later we consider other displays showing that the region perceived as moving and colored need not be bounded by a circular subjective contour.) For this stimulus, observers report that the green region appears to be produced either by a green spotlight roving over the field of red dots or by a moving green filter through which the dots are seen. Dynamic color spreading resembles conventional neon spreading in that it appears transparent (Bressan, 1993; Nakayama, Shimojo, \& Ramachandran, 1990) and is often bounded by illusory contours (Day, 1983; Takeichi, Shimojo, \& Watanabe, 1992; Watanabe \& Sato, 1989; Watanabe \& Takeichi, 1990). Furthermore, dynamic color spreading can be perceived in three dimensions - for example, as covering an ellipsoidal surface which rotates in depth. A similar effect for luminance, without color, is reported by Cortese and Andersen (1991).

In Experiments 1 and 2, we studied dynamic color spreading with the display described above, in which a green region bounded by a subjective contour (henceforth called "the disk") appeared to move over a field of red dots. In these experiments, the size and velocity of the central disk were varied. The results show that the apparent strength of dynamic color spreading depends on the speed of translation of the disk, with little spreading seen at slow speeds and more at high speeds. They also show that the observers' ratings of color spreading depend on the size of the disk, with ratings increasing monotonically as disk size grows to about $1^{\circ}$ of visual angle in diameter and then declining for larger sizes. In Experiments 3 and 4, we explored the strength of the effect with a display of gray dots in a field of red dots. In these experiments, we tested whether achromatic dots could produce dynamic color spreading as effectively as the colored (green) dots. The results show that the effect was weakened but nonetheless 


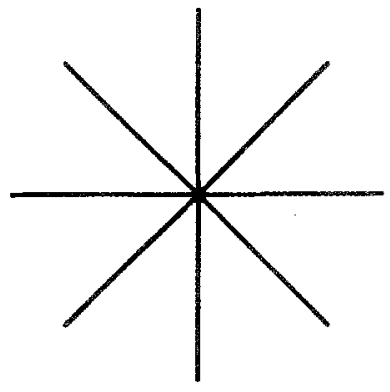

Figure 1. An adaptation of an example of neon color spreading devised by Redies and Spillmann. One sees a green disk, bounded by an illusory contour and centered at the intersection of the four lines. From "The Neon Color Effect in the Ehrenstein Illusion," by C. Redies and L. Spillmann, 1981, Perception, 10, pp. 667-681. Copyright 1981 by Pion Limited, London. Adapted by permission.

present. Ratings of spreading depended on the luminance contrast between the dots within and without the disk. Observers gave higher ratings of its brightness and lower ratings of its saturation if the dots within were more luminous, and just the opposite if the dots within were less luminous. Finally, the results of Experiment 5 demonstrate that successive contrast (as dots change from red to gray) alone cannot explain these findings.

\section{EXPERIMENT 1}

\section{Method}

Observers. The observers for this experiment were two of the authors. Acuity of these two subjects (corrected for D.H. and uncorrected for C.C.) was 20/20. Color vision was within the normal range as assessed by the Farnsworth-Munsell 100-hue test and anomaloscope (Neitz OT) matches. In subsequent experiments, more observers, including some who were naive with respect to the purposes of the experiment, confirmed the findings.

Stimuli and Apparatus. The stimuli were generated by an Apple Macintosh IIx and displayed on a Sony Trinitron color monitor. CIE 1931 (Wyszecki \& Stiles, 1982) coordinates and luminosity values for stimuli used in these experiments were measured with a Spectracolorimeter (Photo Research, PR-650). Each stimulus presentation consisted of 12 frames. Each frame consisted of a white square $\left(5^{\circ}\right.$ of visual angle on each side as viewed from a distance of 44 in.) filled with a random array of 900 dots, each subtending a visual angle of $3^{\prime}$ of arc. Within a circular patch subtending $1.2^{\circ}$ of visual angle, the dots were green $\left(\mathrm{CIE} x=0.272, y=0.583\right.$; luminance $\left.=68.2 \mathrm{~cd} / \mathrm{m}^{2}\right)$; all other dots were red (CIE $x=0.579, y=0.329$; luminance $=20 \mathrm{~cd} / \mathrm{m}^{2}$ ). From frame to frame the location of each dot was held constant, while the assignment of color to dots was progressively changed according to an algorithm (see Appendix A) that colored all dots within a shifting circular area green and all other dots red. In the first frame, the center of the circular region was $0.75^{\circ}$ below the center of the display. On each successive frame, the center of the circular region was moved up $0.125^{\circ}$. The frames were shown cyclically, giving the impression, for sufficiently high speeds, of a disk that moved up and down through the center of the display. Figure 2 shows a reproduction of the first and last frames of one display. The figure accurately portrays the dot density but not the actual colors or luminosities.

Procedures. The observer was instructed to maintain fixation at the center of the display and to rate, on a scale from 0 to 4 , the perceived depth, motion, and spreading of color for each stimulus presentation. Zero was to be used if the observer was absolutely certain of the absence of the attribute, 1 if moderately certain of its absence, 2 if uncertain, 3 if moderately certain of its presence, and 4 if $a b$ solutely certain of its presence. In practice, each observer used the full range of ratings for each attribute (color, motion, depth).

Design. The independent variable was the update rate of the 12 frames in each presentation. There were nine different update rates (equivalent to speeds of $0.063,0.125,0.300,0.675,1.08,1.50,1.88$, 2.53 , and $2.93 \% \mathrm{sec}$ ). Within a session, each of the nine update rates was presented five times in pseudorandom order. The results are based on mean values of the ratings over four sessions.

\section{Results}

In a static view (one frame of the stimulus), the region occupied by the green dots appears to be closer to the ob-
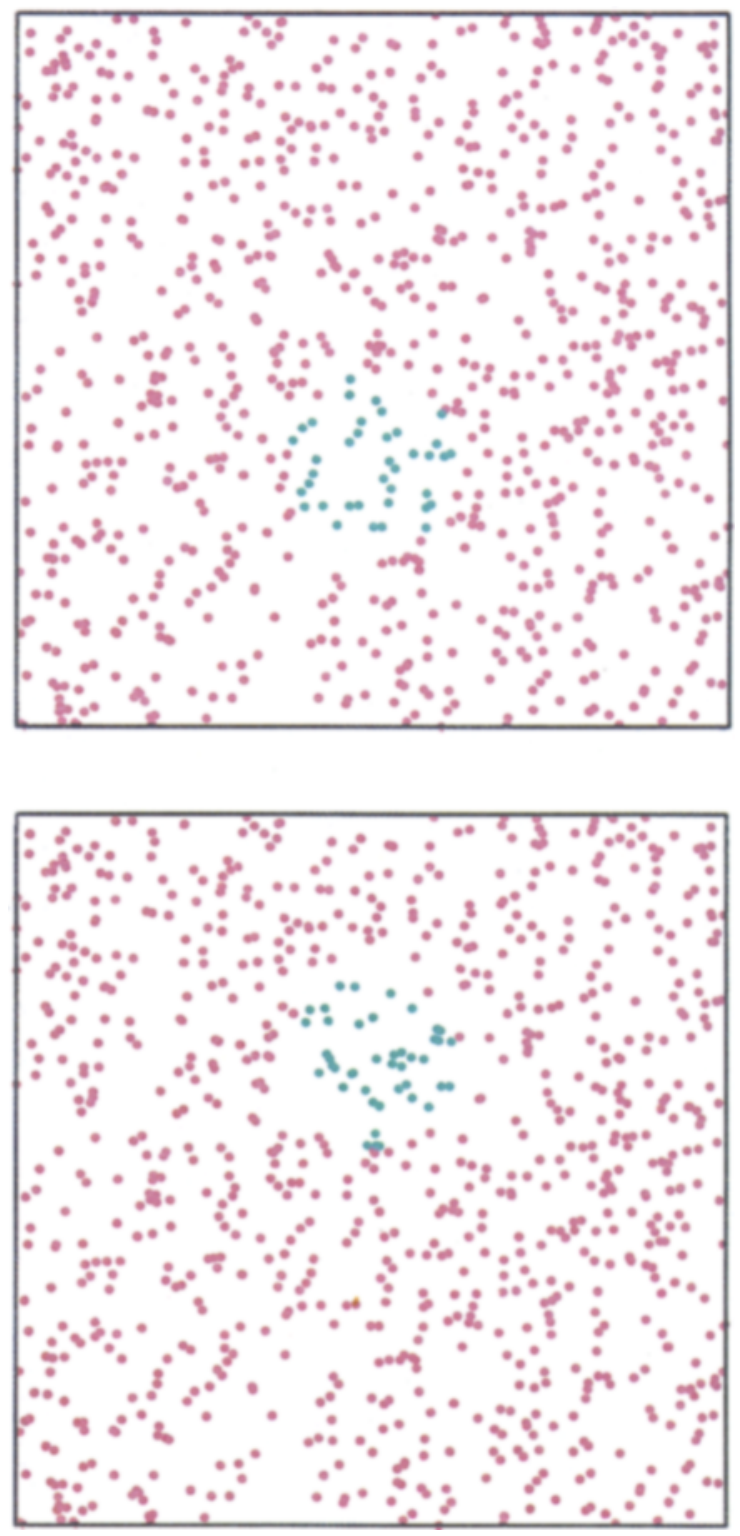

Figure 2. Two frames from a display of dynamic color spreading are shown at top and bottom. When shown in rapid succession, a sequence of such frames leads to the perception of dynamic color spreading. 
server in depth, perhaps because of chromatic aberration. As the update rate is increased, apparent motion and a clear, circular subjective contour are perceived. In addition, a diffuse green color spreads throughout the area defined by the circular, subjective contour. This green disk is described by the observer as if a green filter or a green spotlight were moving over a field of red dots. Furthermore, there is a change in the perceived depth of the green dots from what is seen in the static view: All dots are seen as static and located in a single plane with only the diffusely green circular region moving. The green color is clearly disassociated from the dots and is perceptually linked to the moving disk.

Figure 3 is a composite of the results measured for the 2 observers (C.C. shown at the top and D.H. shown at the
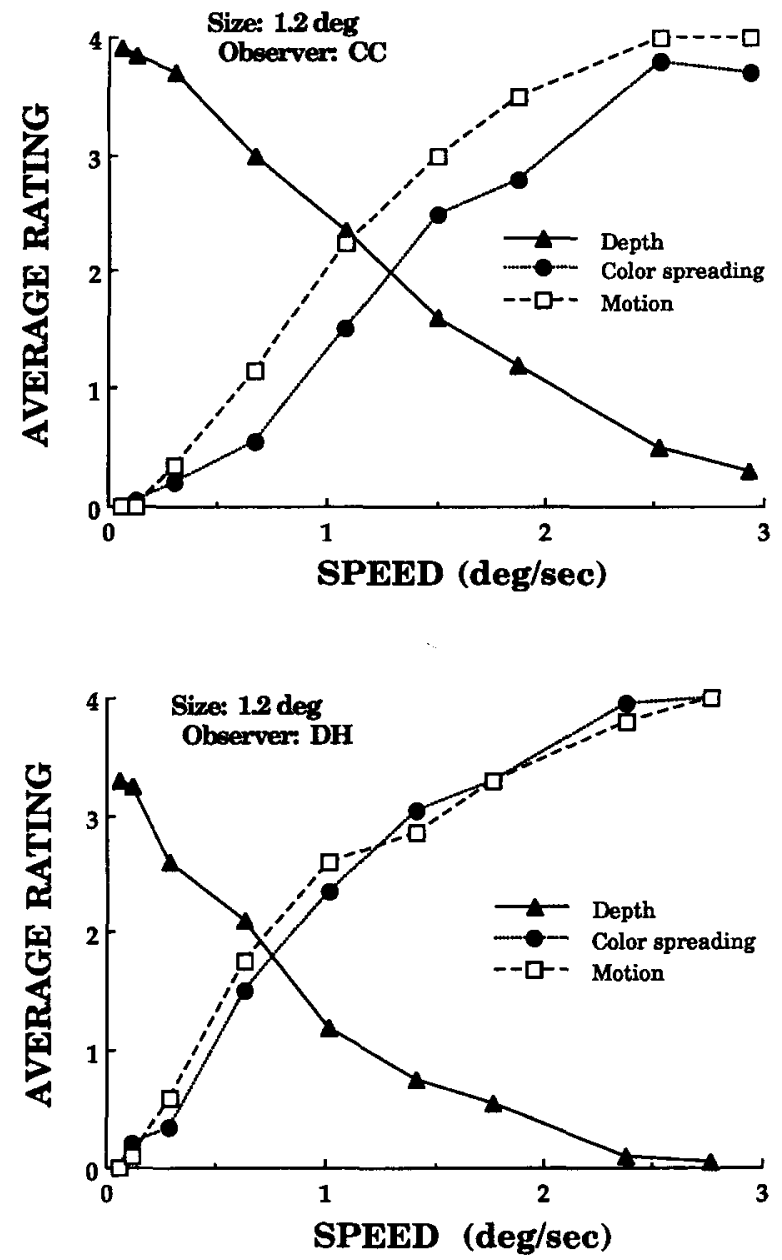

Figure 3. A composite of the results measured for two observers (C.C. shown at the top and D.H. shown at the bottom) in Experiment 1. Each graph plots the ratings for perceived depth, color, and motion as a function of speeds equivalent to the update rates. In this and all subsequent data plots, the standard errors of the means calculated over sessions were roughly the size of the data symbols. bottom). Each graph plots the ratings for perceived depth, color, and motion as a function of speeds equivalent to the update rates. There is good agreement between the $2 \mathrm{ob}-$ servers. As the ratings of perceived motion increase, the ratings of color spreading increase and the ratings of perceived depth differences between the green and the red dots decrease. The rate of increase of color spreading tracks that for the perception of apparent motion in both observers.

\section{Discussion}

As mentioned before, dynamic color spreading refers to the spread of a uniform color in an area defined by motion. The principal finding of Experiment 1 is that the perception of dynamic color spreading is yoked to the perception of apparent motion of the disk in that perception of apparent motion is required for color to spread throughout the disk. The appearance of a subjective contour defined by motion is not new (Kellman \& Cohen, 1984; Klymenko \& Weisstein, 1981; Sekuler \& Levinson, 1977; see also Peterhans \& von der Heydt, 1991), nor is neon color spreading in static displays (Ehrenstein, 1941; Nakayama et al., 1990; Redies \& Spillmann, 1981; van Tuijl, 1975). What is novel is the spread of color within an area defined by motion. This motion-induced reassignment of color is accompanied by a change in the depth relationships among the dots: A depth difference perceived in the static view is abolished when motion and dynamic color spreading are perceived. This is in contrast to the well-known kinetic depth effect, wherein depth relationships which cannot be perceived in a static view can be seen with the aid of motion (Lappin, Doner, \& Kottas, 1980; Ullman, 1979; Wallach \& O'Connell, 1953). This is also in contrast to the displays of Bressan and Vallortigara (1991), in which a bar, produced by neon color spreading in a static display, is seen to slant in depth when the display is rotated. In these previous studies, motion has been used to define contours and depth relationships; what is novel in this study is that motion has been shown to produce the perception of color and color spreading in an area defined by motion.

Furthermore, in dynamic color spreading, the perception of motion of the colored disk produces a redefinition of color and depth for the dots within the disk. In the studies presented here, the dots encompassed by the moving subjective contour appear not to move with the contour but are perceived as stationary, red, and lying in the same plane as are the red surrounding dots. This is in contrast to previously reported displays in which an illusory contour (e.g., a Kanisza triangle) moving against a background of static texture produces an effect known as "motion capture" (Ramachandran, 1986): The static texture appears to move with the encompassing subjective contour. A key difference between these two cases is that in motion capture the illusory contour can be seen without the perception of motion, whereas in dynamic color spreading, the illusory contour is produced by apparent motion. 


\section{EXPERIMENT 2}

\section{Method}

The observers, stimuli, apparatus, and procedures were identical to those of Experiment 1 , except that four diameters $\left(0.30^{\circ}, 0.60^{\circ}\right.$, $1.2^{\circ}$, and $2.4^{\circ}$ of visual angle) of the circular region were used in order to determine the spatial extent of this effect. In each experimental session an observer viewed four sets of stimuli, one for each diameter. The results are based on four experimental sessions.

\section{Results}

The results are summarized in Figure 4, in which the ratings of color spreading for these four stimulus sizes are compared. Within the range of stimulus sizes, the $1.2^{\circ}$ stimulus is optimal in producing the most compelling perception of apparent motion and subjective contour as well as color spreading. This size also produces the greatest reduction in perceived difference in depth between the differently colored dots in comparison with what is seen with the static view. For Observer C.C. the $0.3^{\circ}$ and $0.6^{\circ}$ stim-
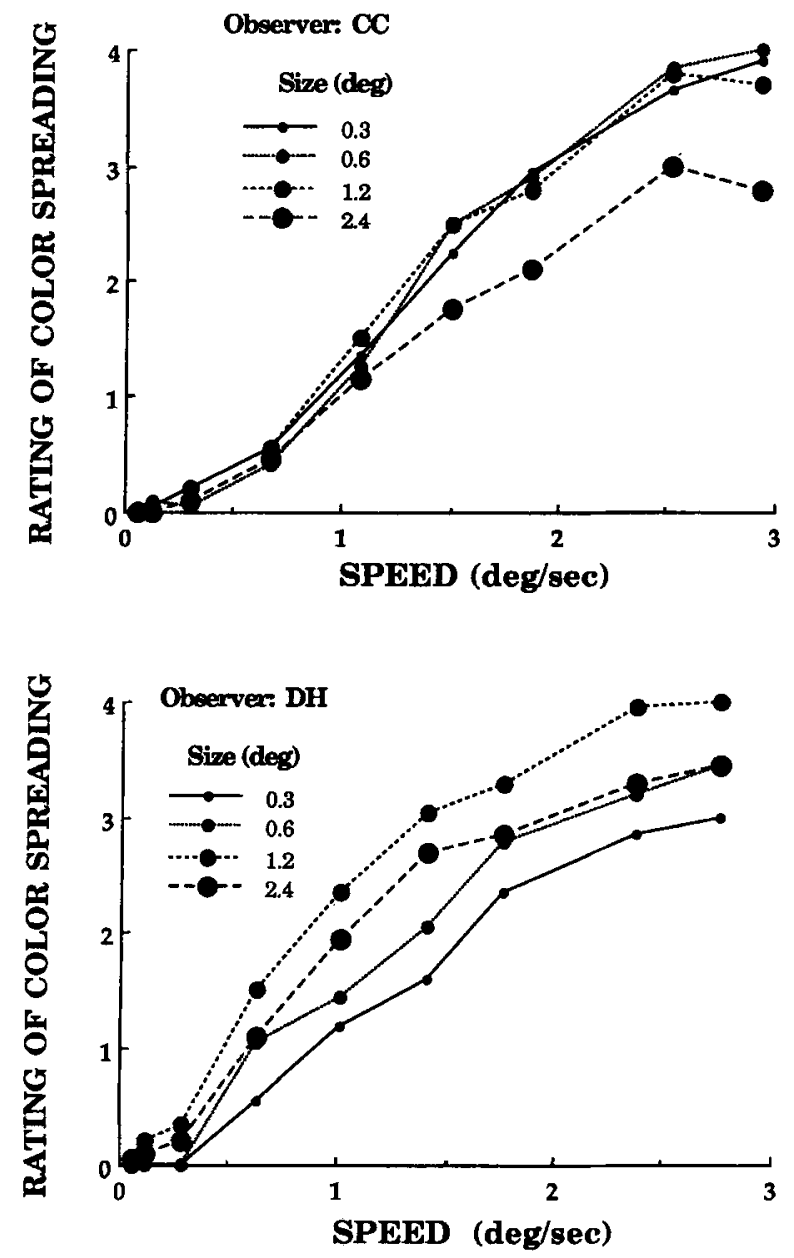

Figure 4. Comparison of the ratings of color spreading for four stimulus sizes for each observer in Experiment 2. Within this range of stimulus sizes, the $1.2^{\circ}$ stimulus is optimal in producing the most compelling perception of apparent motion and subjective contour as well as color spreading. uli produce results comparable to those for the $1.2^{\circ} \mathrm{stim}$ ulus, whereas there was a consistent decrement for the $2.4^{\circ}$ stimulus measured at all speeds. Observer D.H.'s results show a progressive enhancement of color spreading with sizes increasing from $0.3^{\circ}$ to $0.6^{\circ}$ and $1.2^{\circ}$, until a decrement is measured for a stimulus size of $2.4^{\circ}$.

\section{Discussion}

Within the range of sizes that we employed, the $1.2^{\circ}$ stimulus produced the maximal effect for both observers although all sizes were effective. These results are consistent with the conclusion that the effect is not likely to be retinally based, inasmuch as the sizes of receptive fields of retinal ganglion cells in central areas of the primate retina are known to be considerably smaller than the smallest of our stimulus sizes (Croner \& Kaplan, 1995; Crook, Lange-Malecki, Lee, \& Valberg, 1988; DeMonasterio \& Gouras, 1975; Hubel \& Wiesel, 1960). On the other hand, the high degree of convergence from retina to higher levels in the visual pathway and the reported increase in the sizes of receptive fields at higher sites point to a more central locus of the effect. For example, the linear dimensions of receptive fields at the level of V4 (see, e.g., DeMonasterio \& Schein, 1982) and MT (see, e.g., Mikami, Newsome, \& Wurtz, 1986) are reported to be several multiples of those for the receptive fields of cells in V1 for comparable eccentricities.

\section{EXPERIMENT 3}

In Experiments 1 and 2, a circular array of green dots in a field of red dots was used. In Experiment 3, we used an achromatic central area of gray dots (rather than green) embedded within a field of red dots. As described above, dots did not change location from frame to frame; only color assignments changed. Thus, when red dots were reassigned to gray, by successive contrast these gray dots should appear greenish. It is also the case that the surrounding red dots might produce a perceived greenish color of the gray dots by simultaneous contrast. As a result, even in the absence of dots physically colored green, the color spreading might occur. In Experiment 3, we measured the perceived color of the gray dots in our apparent motion paradigm. In Experiment 4, we measured the extent of color spreading in the area occupied by the gray dots.

\section{Method}

Observers. There were 6 observers for this experiment, 4 of whom were the authors and 2 of whom (J.L. and G.B.) were without prior knowledge of the purposes of the experiments. The acuity of these obervers was $20 / 20$. Their color vision was within the normal range as assessed by the Farnsworth-Munsell 100-hue test and anomaloscope (Neitz OT) matches.

Stimuli and Apparatus. All aspects of the stimuli and apparatus were identical to those for Experiments 1 and 2, with the following exceptions. Each stimulus display consisted of a circular patch of randomly scattered gray dots in a surrounding square field of randomly scattered red dots. The circular patch was held constant at $1^{\circ}$ of visual angle in size. The update rate was held constant at a 
rate equivalent to $2.93^{\circ}$ per second for the 12 frames of the display. This led to a clear perception of apparent motion for all observers. Five different luminance levels of the gray dots were presented.

Procedures. The observers were instructed to make color matches to the gray dots when they were viewed in the static condition and when they were viewed in apparent motion. In each of four experimental sessions, an observer viewed five sets of stimuli, one for each luminance level of the gray dots. Hue, saturation, and brightness were separately matched to a comparison stimulus in a staircase procedure. The comparison stimulus, presented on a Sony Trinitron monitor with 24-bit specification of color, was a uniformly colored disk, size matched to the circular $1^{\circ}$ patch of gray dots. The locations of selected stimuli are plotted in CIE 1931 (Wyszecki \& Stiles, 1982) space in Figure 5. Stimuli were specified by the Mathematica HSB coordinates, where $\mathrm{H}$ is roughly equivalent to hue, $\mathrm{S}$ to saturation, and $\mathrm{B}$ to brightness, and each scale runs from 0 to 1 . Saturations in increments of 0.1 in a range from 0 to 1 are plotted for stimuli designated as Mathematica red, green, and blue. Also noted are the CIE white point and the location (nearby) of the gray stimulus in this space. The CIE 1931 coordinates for all data points are given in Appendix B. All results are plotted in Mathematica HSB space and in CIE space.

\section{Results}

The point of equiluminance between the gray dots and the red was measured independently for 4 of the observers ( 2 other observers left the experiments early) using heterochromatic flicker photometry. These values are marked by arrows in the following figures. Figure 6 is a composite of the results for the 6 observers in static view. In static view, the gray dots are matched to a gray patch of increasing brightness, paralleling the increase in luminance of the gray dots. For 4 observers, saturation and hue are unaffected by increases in luminance of the gray dots. For

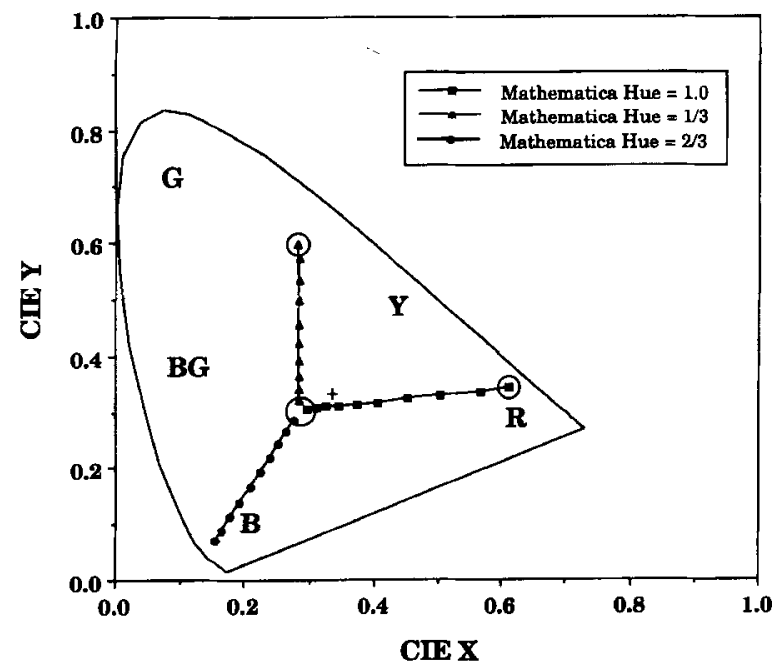

Figure 5. Mathematica red, green, and blue stimuli plotted in CIE 1931 space for saturation ranging between Mathematica scale $0-1$ in steps of 0.1 . The circled end points for the red and green lines mark the stimuli employed. The circled area at the intersection of the red, green, and blue lines shows the region where the gray stimuli are located. The small cross marks the white point. The other letters refer to the general hue in that region of the space (e.g., "BG" for blue green, "R" for red, etc.).
2 observers (P.G. and G.B.), the surrounding red dots produce significant simultaneous color induction in the gray dots for lower luminance values, and this is reflected as decreases in judged saturation as a function of increases in luminance of gray dots. The same data are plotted in CIE space in Figure 7.

In the apparent motion display (Figure 8), when the luminance of the gray dots is less than that of the red dots, the gray dots are matched by each observer to a highly saturated, bluish-green color. As the luminance of the gray dots increases, the perceived saturation decreases. These data are plotted in CIE space in Figure 9.

\section{Discussion}

The measurements in Figures 6 and 7 indicate the amount of simultaneous color contrast induced by the red dots. This was small for all but 2 observers (G.B. and P.G.). For most observers, the brightness required to match the gray dots increases as the gray dot luminance increases, whereas the hue and saturation in the matching stimulus remains constant. For Observer P.G., the static display produces significant simultaneous color contrast in that high levels of saturation are required in the matching stimulus when the central gray dots are set at a luminance equal to or lower than that of the surrounding red dots.

All observers show a significant effect of color induction in the apparent motion display. Judged hue is constant as a function of gray dot luminance level, while judged saturation varies. For lower luminance levels, judged saturation is high; as the luminance of the gray dots increases, saturation decreases. A comparison of Figures 6 and 8 shows that the judged saturation is greater in the apparent motion condition than in the static condition.

\section{EXPERIMENT 4}

\section{Method}

The observers, stimuli, and apparatus were identical to those of Experiment 3. The procedures were identical, except that the observers were asked to judge the extent of color spreading.

\section{Results}

Figure 10 shows the results of Experiment 4 . If the gray dots are more luminous than the red, then one perceives, along with apparent motion, a circular region throughout which spreads a desaturated blue-green color. As described before, this region appears as a transparent filter or as a spotlight moving over the dots. As the luminance of the gray dots increases, the color spreading appears further desaturated, more highly luminous, and bounded by a subjective contour. The desaturation of color spreading parallels the reduction in motion-induced saturation of the dots themselves as the luminance of the dots is increased (Experiment 3). Observers require less saturation to match color spreading than they require to match the perceived color of the dots. Figure 11 shows these results in CIE space. 


\section{Condition: Static Dots}
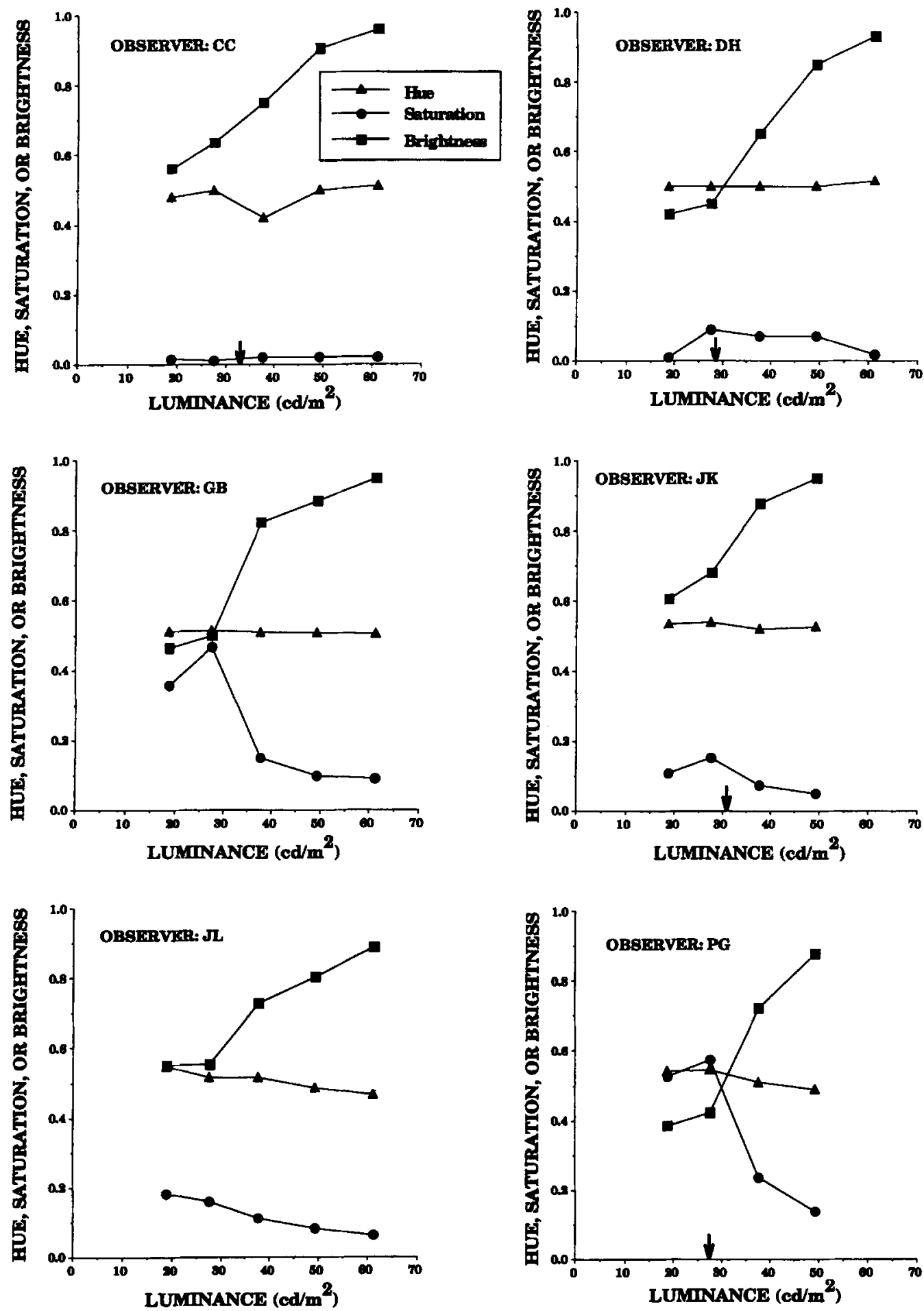

Figure 6. Hue, saturation, and brightness of color matches to the gray dots in the static condition. The graphs show the results for each of 6 observers in Experiment 3. The arrows indicate the luminance value for gray dots which each observer matches to the luminance of the red dots. 


\section{Discussion}

For most observers, subjective contours are perceived when the gray dots are more luminous than the surrounding red dots. For all observers, the saturation perceived in dynamic color spreading over the central gray dots is much less than that seen if the central dots are green (as in Experiments 1 and 2). Nonetheless, observers perceive a distinct bluish-green color spreading over the gray dots, as can be seen in Figure 12, in which all data points from Experiments 3 and 4 are plotted in CIE space for a representative observer. All data points lie on a line passing close to the CIE white point, indicating that the same hue is perceived; only saturation changes as the luminance of the gray dots is varied. The motion-induced blue green

\section{Condition: Static Dots}
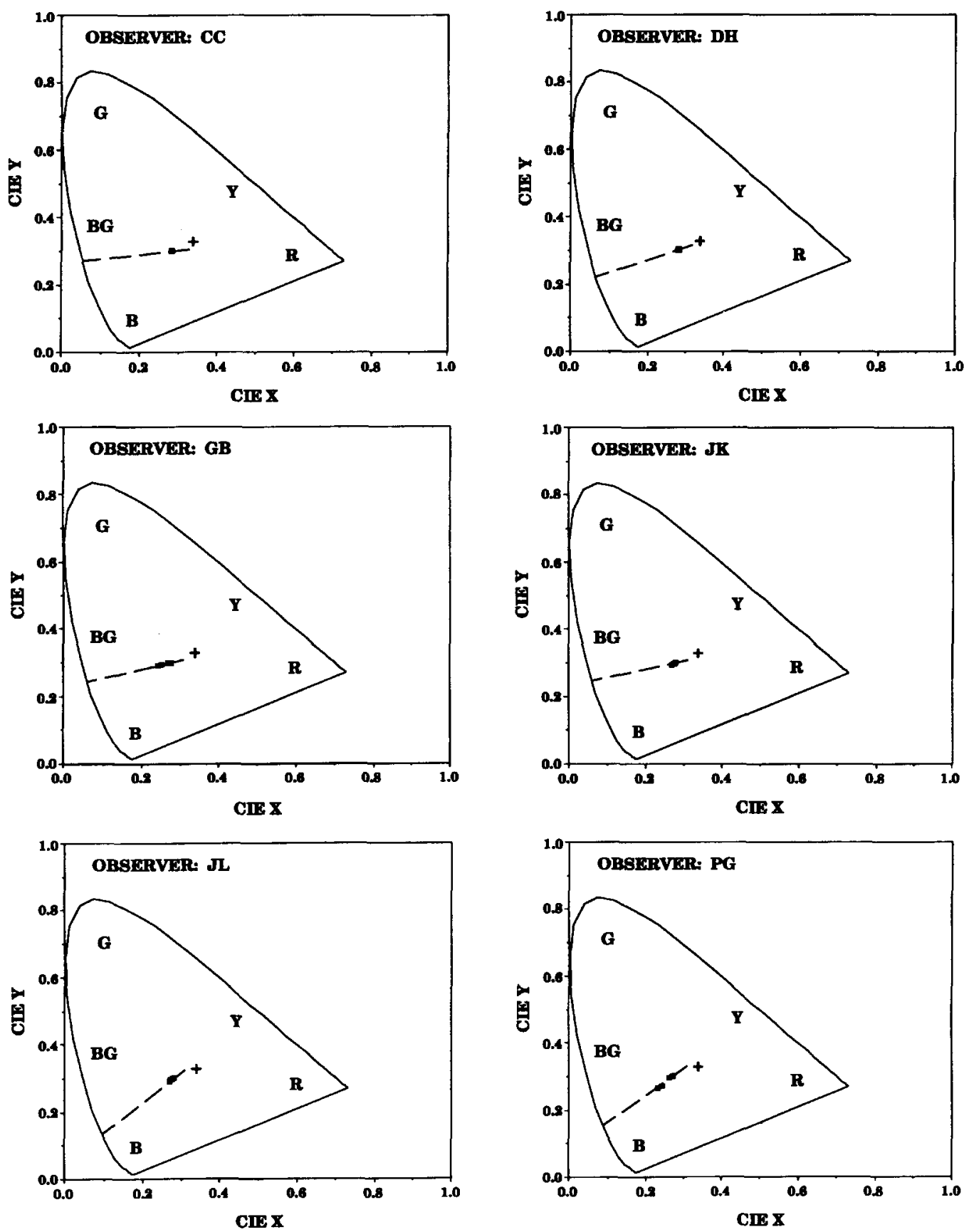

Figure 7. Color matches to the gray dots in the static condition plotted in CIE 1931 space for each observer in Experiment 3. The straight line drawn through the data is the best-fitting line (least squares). 
of the gray dots themselves has a higher saturation than does the motion-induced blue green of the dynamic color spreading.

Luminance contrast is known to be critical for the formation of static subjective contours (Gregory, 1977), the perception of apparent motion (Cavanagh, Boeglin, \&
Favreau, 1985; Ramachandran \& Gregory, 1978), and neon color spreading (Bressan, 1993). As shown in Experiments 3 and 4 , luminance contrast is also critical for motion-induced color spreading.

In our displays, we did not systematically study the conditions under which a subjective contour appears. How-

\section{Condition: Motion Dots}
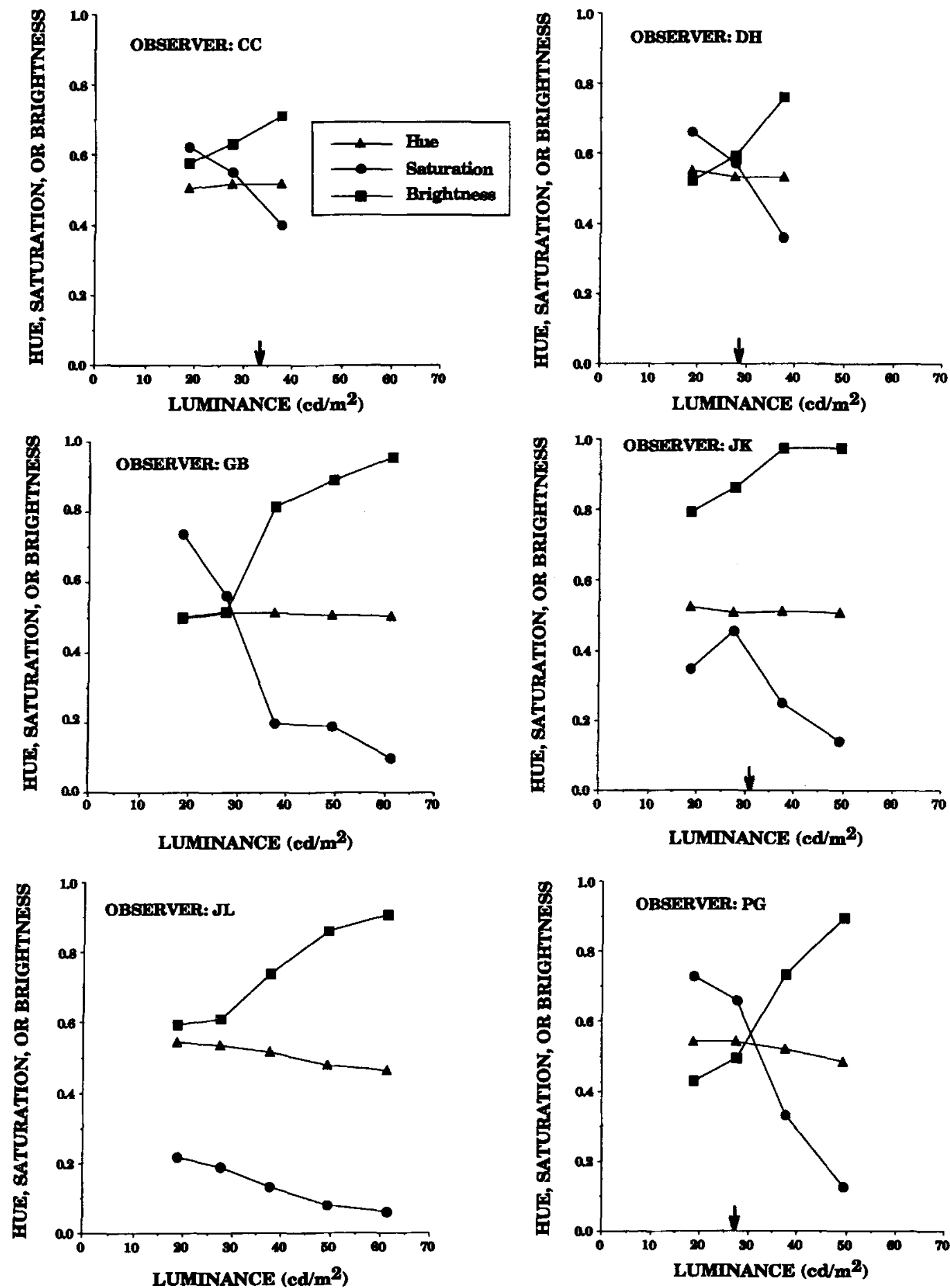

Figure 8. Hue, saturation, and brightness of color matches to the gray dots in the motion condition of Experiment 3. 
ever, we note the following: As documented above, if the central dots are more luminous than the surrounding dots, the perception of motion induces a clear subjective contour, a blue-green color in the central gray dots, and dynamic color spreading. Near isoluminance, the perception of motion and of a subjective contour is decreased for all observers and eliminated altogether for some. Concommitantly, color spreading ceases. If the central dots-whether gray or green-are of luminance well below that of the surrounding dots, then apparent motion and dynamic color spreading are seen without a subjective contour.

If the surrounding red dots are made more luminous than the central gray (or green) ones, some observers report seeing amodal completion, as has also been reported for static color spreading (Fujita, 1993; Nakayama et al., 1990; Yamada, Fujita, \& Masuda, 1993). One sees a white

\section{Condition: Motion Dots}
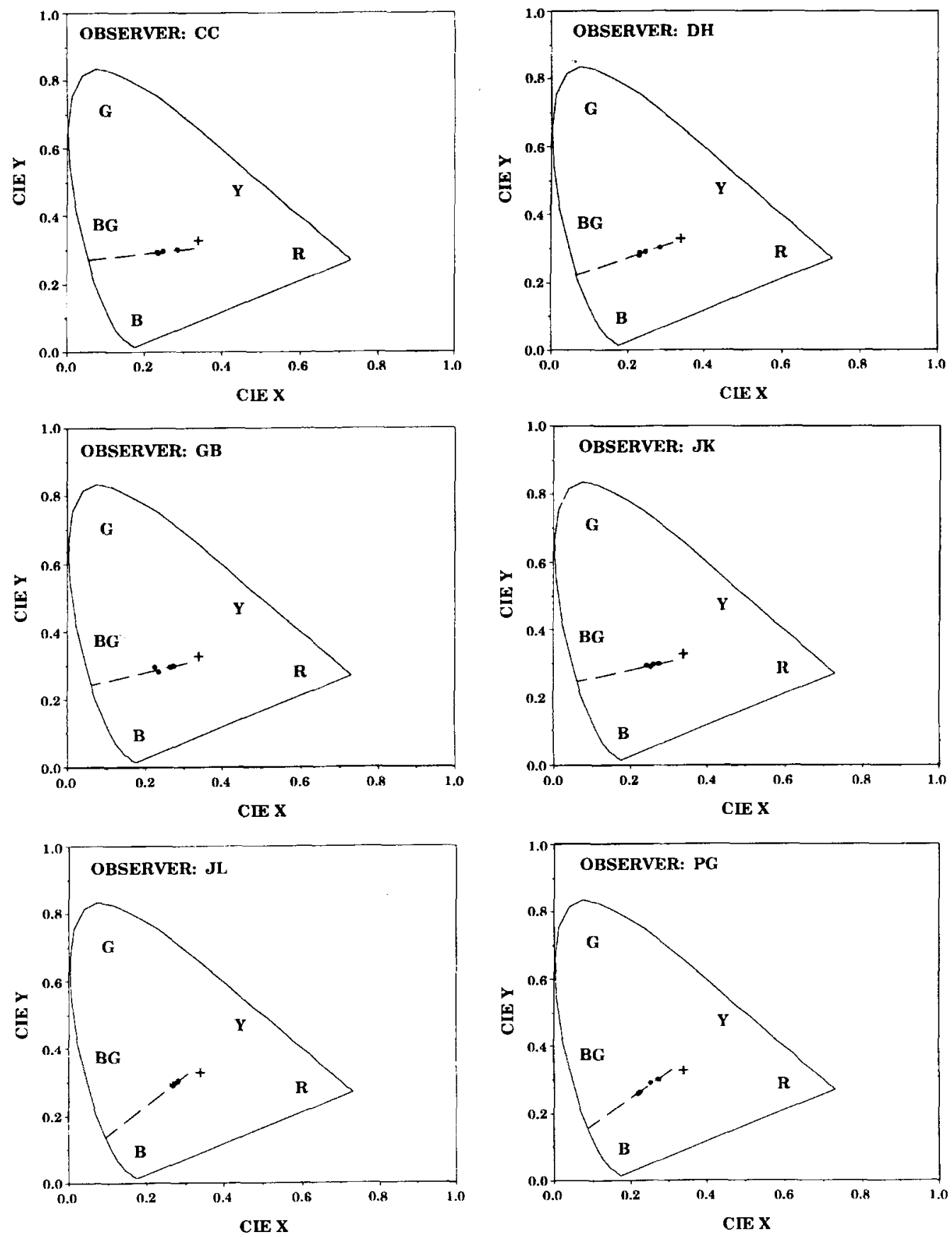

Figure 9. Color matches to the gray dots in the motion condition plotted in CIE 1931 space for each observer in Experiment 3. 
sheet with small holes punched in it. Behind this white sheet, and visible only through the small holes, is a solid green disk moving over a solid red field. The saturations of the solid green disk and the solid red field appear to match those of the green and red dots, respectively, in the display. The green of this disk in the amodal perception is more highly saturated than the green when color spreading is perceived.
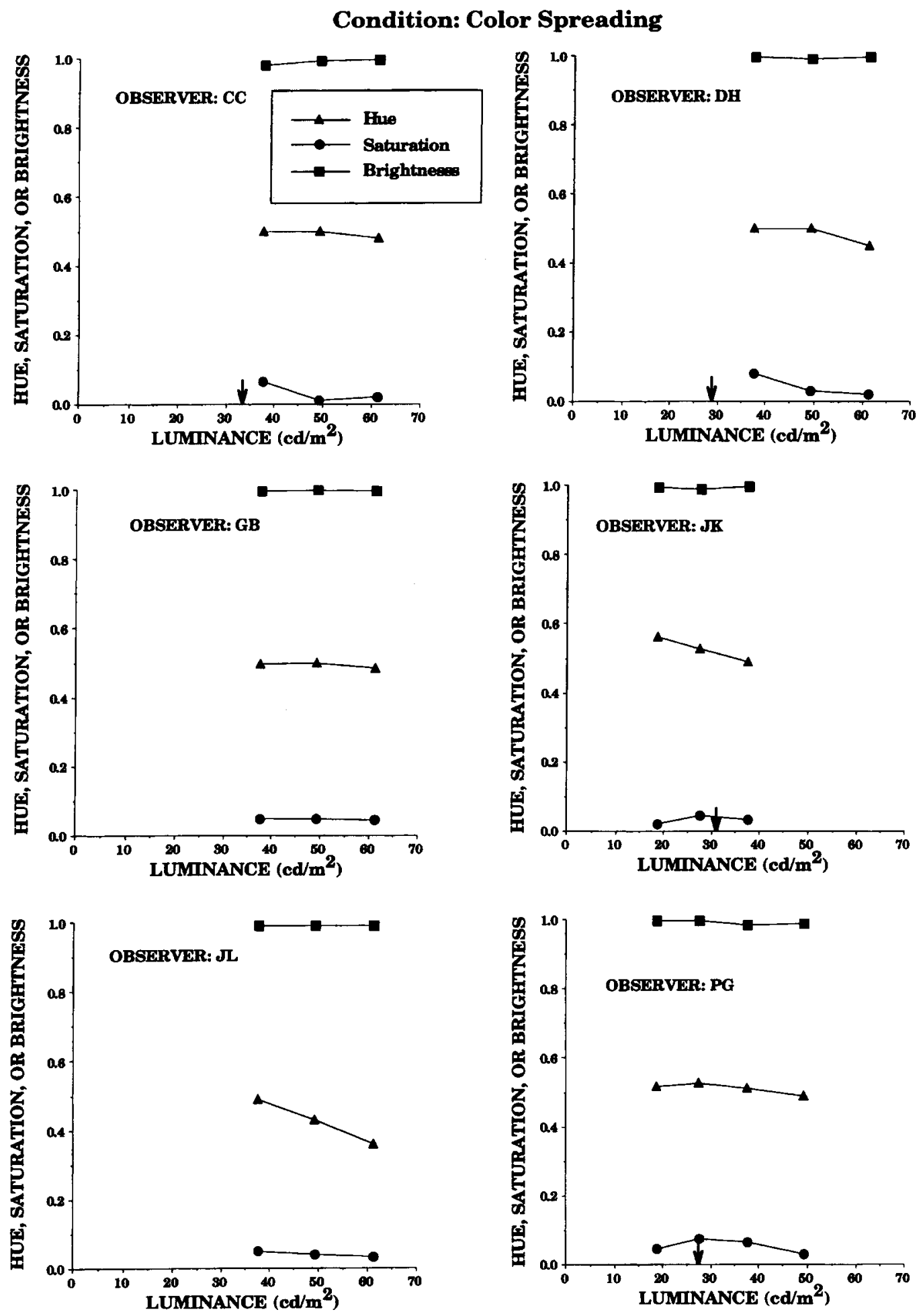

Figure 10. Hue, saturation, and brightness of color matches to the dynamic color spreading in Experiment 4. 


\section{EXPERIMENT 5}

Successive color contrast might have contributed to the effects reported for Experiments $1-4$ in that there were changes in color assignments to dots from frame to frame. For dots whose color assignments changed from red to gray (or green), successive color contrast may have contributed to the perceived blue-green color of the dots in the motion condition. The dots at the leading edge of the disk go through the color transformation from red to gray (or green), but about as many dots at its trailing edge go from gray (or green) to red and some dots in its central area remain gray (or green). No observer noted color nonuniformities in the region of the disk either in the dots themselves or in the color spreading. Therefore, it is unlikely that successive color contrast plays a significant role. Nonetheless,

\section{Condition: Color Spreading}
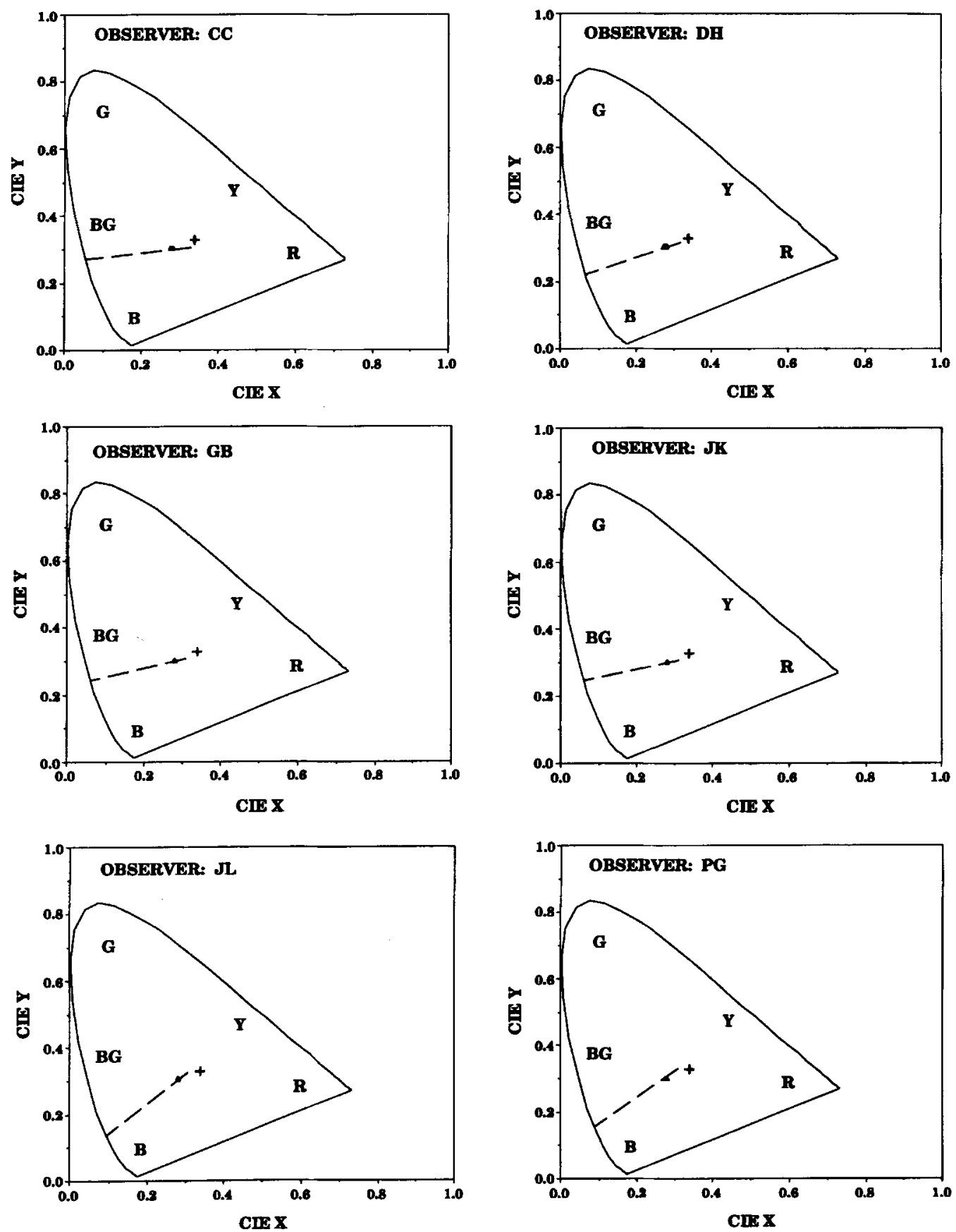

Figure 11. Color matches to the dynamic color spreading plotted in CIE 1931 space for each observer in Experiment 4. 


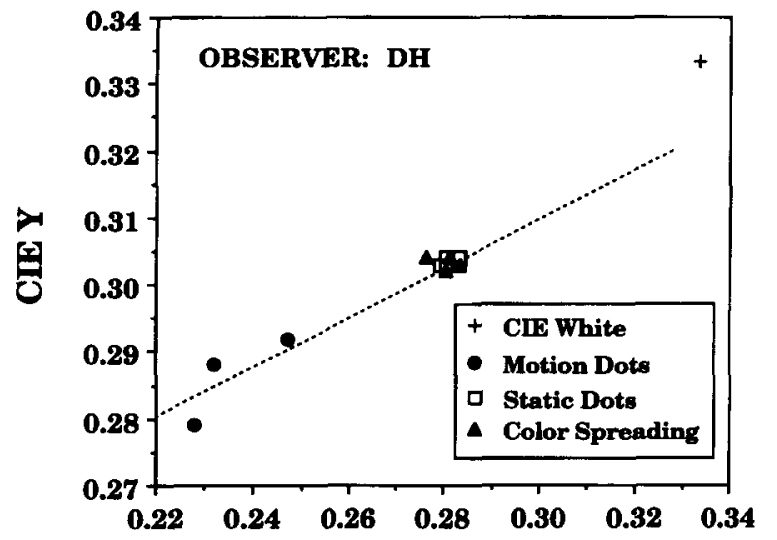

\section{CIE X}

Figure 12. Color matches for all conditions plotted in CIE 1931 space for representative Observer D.H. The straight line through the data is the best-fitting line $\left(R^{2}=.923\right)$ based on this observer's results. The line through each observer's data in Figures 7,9 , and 11 is the best-fitting line based on that observer's results for all conditions of Experiments 3 and 4.

in Experiment 5, we examined the extent to which successive color contrast played a role in these experiments.

\section{Method}

Observers. P.G. and J.K. served as observers for this experiment.

Stimuli and Apparatus. In order to remove possible effects of successive contrast, the stimulus was modified in the following way. As shown in Figure 13 (see color plate), all dots contained within the central, rectangular area over which the disk traversed were removed, except for the dots within the disk. As before, no dots moved; dots within the circular region appeared and were colored gray, or they disappeared. Otherwise the stimuli and apparatus were the same as in Experiments 3 and 4.

Procedures. The procedures were identical to those for Experiment 3

\section{Results and Discussion}

Figure 14 shows the perceived hue, saturation, and brightness of the dots in static view and in apparent motion. The perceived hue remains constant in both conditions for all luminance levels of the gray dots. The perceived brightness increases as the luminance of the gray dots increases in roughly the same way for both conditions. The perceived saturation decreases as the luminance of the gray dots increases in both conditions. The increment in saturation for a fixed level of gray dot luminance in the motion condition in comparison with the static condition is comparable to that measured in Experiment 3. Thus, in the absence of successive contrast, the perception of apparent motion produced an increase in the perceived saturation of the blue-green hue. This suggests that successive color contrast was not a significant factor in the earlier experiments. This leaves simultaneous color contrast as the likely mechanism for inducing the blue-green color in the gray dots. What is interesting is that in most observers, color induction occurred only in the apparent motion condition, not in static view.

\section{GENERAL DISCUSSION}

The principal finding of Experiment 1 is that the perception of dynamic color spreading is yoked to the perception of apparent motion: As the ratings of perceived motion increased, the ratings of color spreading increased and the ratings of perceived depth difference between the dots colored red and the dots colored green decreased (Figure 3). The spatial extent of this effect was determined in Experiment 2 by varying the areas occupied by the green dots. For areas of diameters ranging between $0.3^{\circ}$ to $2.4^{\circ}$ in
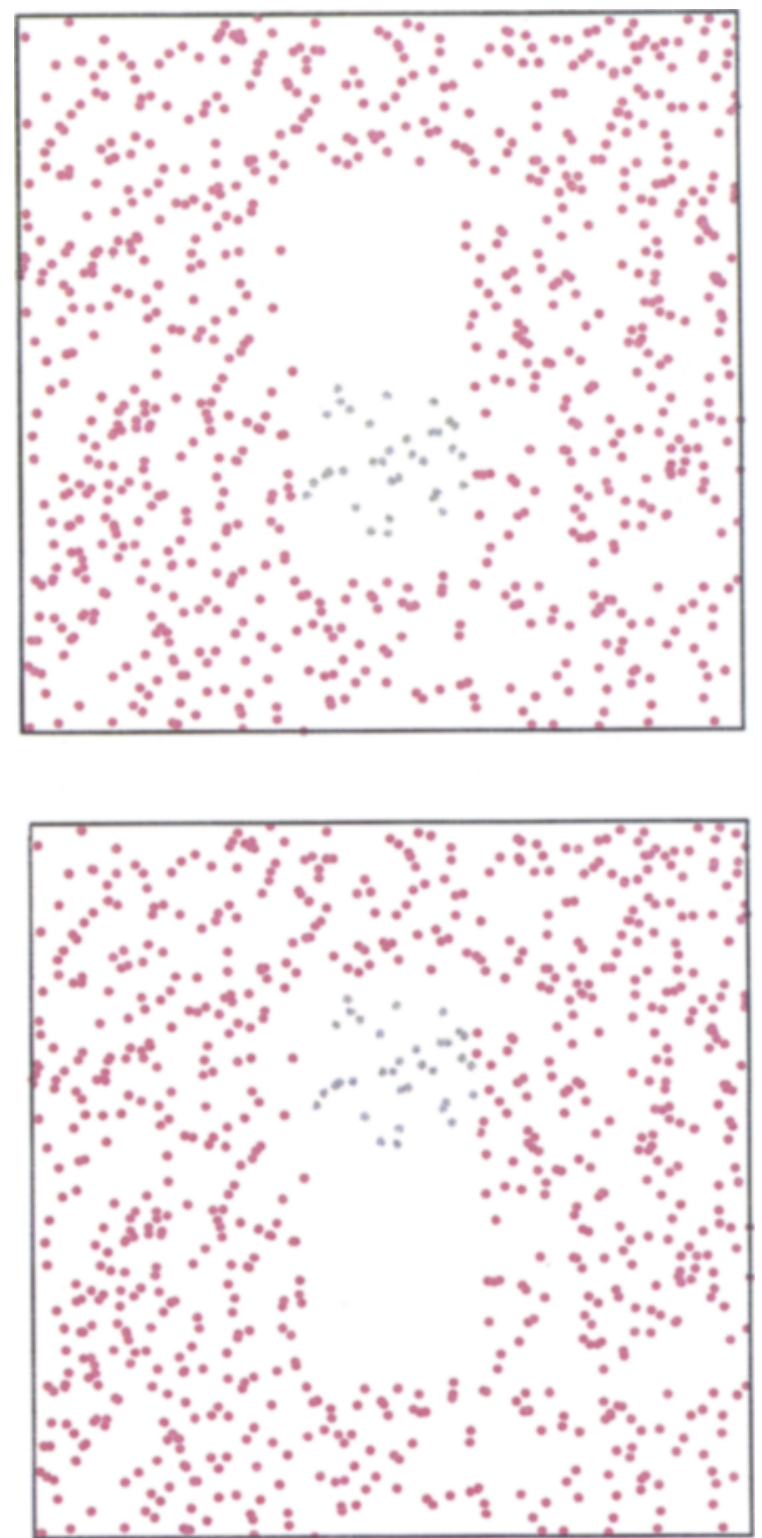

Figure 13. Two frames from the stimulus used in Experiment 5 are shown at top and bottom. All dots contained within the central, rectangular area over which the disk traversed were removed, except for the dots within the disk. As before, no dots moved; dots within the circular area appeared and were colored gray, or they disappeared. 

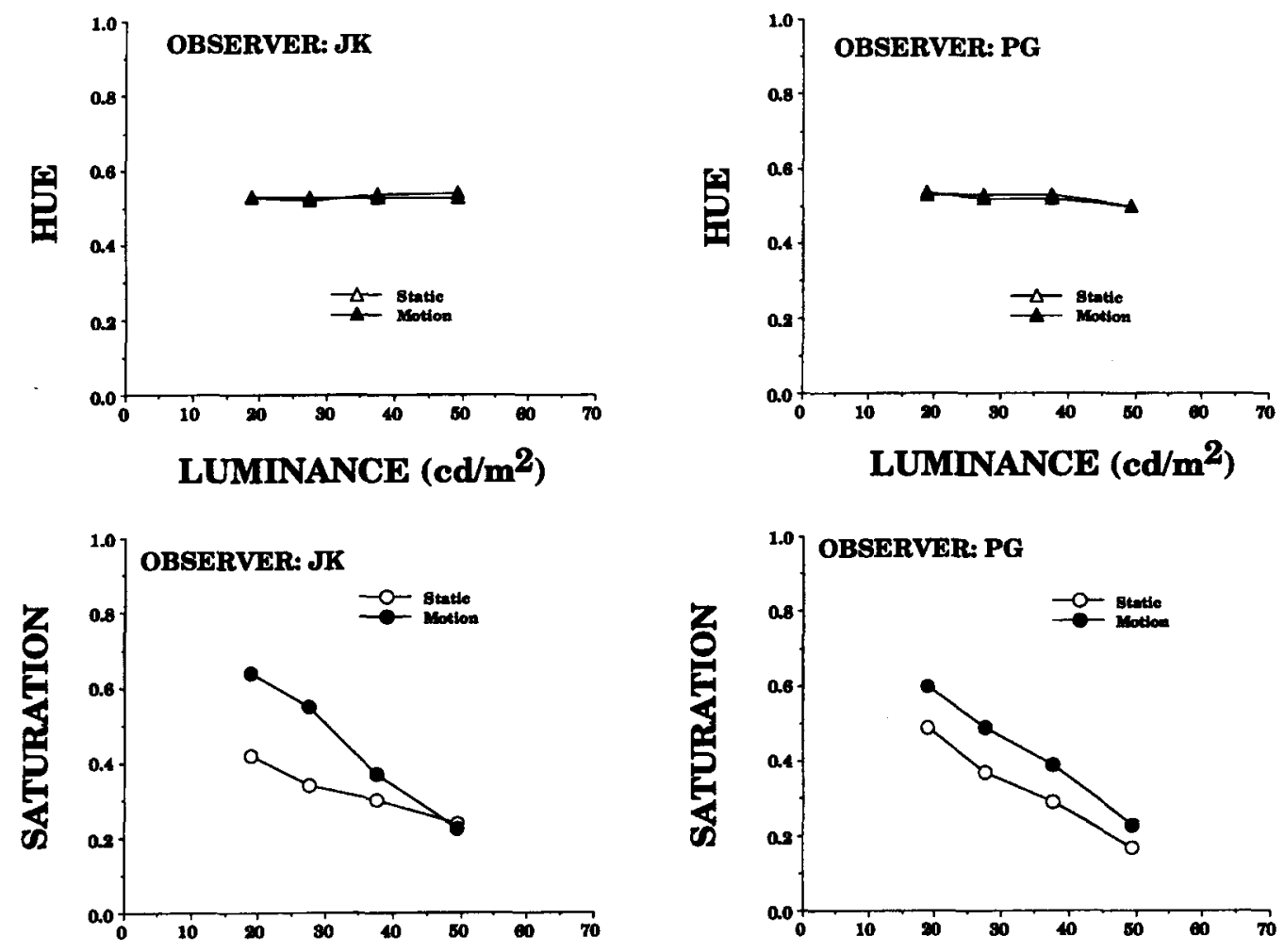

LUMINANCE $\left(\mathrm{cd} / \mathrm{m}^{2}\right)$

LUMINANCE $\left(\mathrm{cd} / \mathrm{m}^{2}\right)$
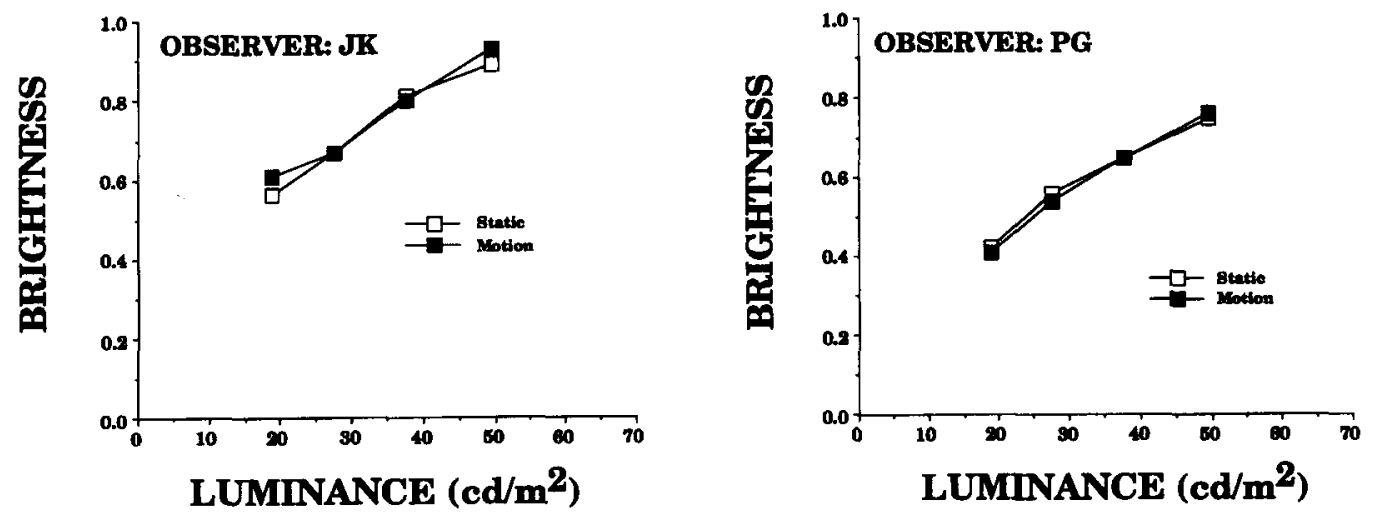

Figure 14. Comparison between the static and motion conditions of Experiment 5 . Hue, saturation, and brightness of the color matches to the gray dots in the static and motion conditions are compared.

diameter, the $1.2^{\circ}$ stimulus produced the most compelling color spreading (Figure 4). Experiments 3 and 4 show that the effects observed in Experiments 1 and 2 can be produced with an achromatic central area of gray, rather than green, dots. In static views, observers matched the gray dots to a gray or a desaturated bluish green (Figures 5 and 6 ), whereas in the apparent motion displays, observers matched the gray dots to the same hue and brightness as in the static case but to a higher saturation (Figures 7 and 8 ). The effect was greatest when the gray dots' luminance was less than that of the red dots. As the luminance of the gray dots increased, perceived saturation decreased. The satura- tion perceived in the spreading was much less than that seen in Experiments 1 and 2 with green dots. Finally, Experiment 5 demonstrated that successive color contrast alone cannot explain motion-induced color spreading.

Our main finding - that the perception of motion can produce new conjunctions of color and form-provides perceptual evidence for interactions between motion and color pathways. Physiological and perceptual evidence has rapidly accumulated for a scheme of organization of the primate visual system into such multiple neural pathways (see, e.g., DeYoe \& Van Essen, 1985; Lennie, Trevarthen, Van Essen, \& Wassle, 1990; Livingstone \& 
Hubel, 1988; Shapley \& Perry, 1986; Shipp \& Zeki, 1985; Treisman, 1982). Each of these pathways, based on classes of neurons with distinctive properties and roles, provides a specialized representation for the analysis of aspects-for example, motion or color-of the visual world. In everyday life, a smooth interleaving of the information provided by these parallel pathways leaves us generally unaware of this specialization of function.

The parvocellular and magnocellular pathways have been identified as two main streams which convey information from the retina, through the lateral geniculate nucleus, to the primary visual cortex (see, e.g., Lennie et al., 1990; Shapley \& Perry, 1986). A number of subsequent locations in the visual brain receive, reorganize, and send on the information carried by these two streams. In particular, many cells, tured for velocity, are located in the medial temporal sulcus in the area known as MT (Dubner \& Zeki, 1971; Newsome, Wurtz, Dursteler, \& Mikami, 1985), which has been linked to the perception of motion (Movshon, Adelson, Gizzi, \& Newsome, 1986; Newsome \& Pare, 1988). Furthermore, activation of MT has been specifically linked to figure-ground segregation and the perception of structure from motion (Allman, Miezin, \& McGuinness, 1985; Tanaka et al., 1986). The perceptual observations reported here suggest that the motion pathway is involved in the visual system's interpretation of the two-dimensional retinal image in terms of form, color, and depth. One explanation for the results reported here is that activation of the motion pathway triggers a reorganization of the stimulus features so that new conjunctions are perceived. As can be seen most vividly with the stimuli of Experiments 1 and 2, there are a number of signs that this has occurred. First the green color is disassociated from the dots themselves and a green patch is perceived to move, independently of the static dots. Second, there is a change in the perceived depth of the green dots; in the static display, the green dots are perceived as lying in front of the red dots, but in the motion display, they are perceived as lying in the same plane as the red dots. Finally, all dots appear red in the motion display; the green color is disassociated from the dots and linked to the percept of a uniformly colored, green circular patch moving over the red dots.

The processing of color information is usually associated with the parvocellular stream. The magnocellular stream is believed to subserve the processing of visual information related to luminosity, motion, pattern, some kinds of depth, and vernier acuity. In our display, the perception of motion precedes the spread of color within a region defined by motion. If the central dots are more luminous than the surround dots, then a subjective contour bounding this region is seen. When the subjective contour and the subjective color define the green disk as a figure, separate from the dots, all dots appear to be colored red and appear to lie in the same plane. We suggest that the neurophysiological correlate of these perceptual events involves the activation of cells with receptive fields larger than the 3'-of-arc diameter of the dots. According to this view, the boundaries of these larger receptive fields are roughly commensurate with the area defined by motion over which color spreads. Here we point to the results in Figure 3, which show that the effect was obtained for stimuli ranging between $0.3^{\circ}$ and $2.4^{\circ}$ in linear extent. It is interesting that both observers reported uniform color spreading throughout the $1.2^{\circ}$ stimulus but often patchy color over the extent of the $2.4^{\circ}$ stimulus. Moreover, perceived depth of the green dots did not clearly change in conjunction with the perception of motion for the $2.4^{\circ}$ stimulus. Thus, we propose that in the static view the dots in the stimulus are seen as red or green probably by virtue of processing in the parvocellular stream. When the perception of motion defines the green disk, color is disassociated from the small dots and is spread throughout the extent of the larger disk. Our suggestion is that the extent of color spreading may be determined by the dimensions of the receptive fields of cells in the motion pathway. These results could be accomodated within a framework in which the parvocellular stream provides some input to the motion pathway, generally thought to receive most, perhaps all, its input from the magnocellular stream.

Challenges to the notion of strict segregation of pathways for the perception of properties such as motion or color have recently gained ground. Stoner and Albright (1993) reject standard models which have specified that motion processing is based solely on luminance variations in the image. Their proposal rests on evidence that the processing of visual motion is dependent on the segmentation of the visual image according to cues such as color and depth (see, e.g., Dobkins \& Albright, 1993; Kersten, Bülthoff, Schwartz, \& Kurtz, 1992; Kooi, DeValois, Switkes, \& Grosof, 1992; Krauskopf \& Farell, 1990; Nakayama \& Shimojo, 1990; Trueswell \& Hayhoe, 1993). Instead, they propose that motion detection has access to a variety of image cues and that motion integration is influenced by image segmentation processes (such as transparency) previously thought to be processed independently of motion.

Our results provide a different kind of challenge to the idea of segregated processing pathways for color and motion: In our results, the perception of motion drives the perception of color. This interaction between the processing of color and motion is likely to occur at a central site because dynamic color spreading is seen most vividly with stimulus sizes near $1^{\circ}$, too large for any but central receptive fields (Experiment 2). Thus, our results are consistent with the evidence from other studies cited above in showing an interaction between pathways at central processing sites. Our results are different from the previous findings in the following way: The results from other studies show that a variety of image cues - not solely luminance contrast - can influence the perception of motion, whereas we show the reverse, that the perception of motion can drive the perception of color, of the spread of color, and of depth relationships in a region defined by motion. Furthermore, as mentioned before, the finding that color spreads throughout a region defined by motion suggests that the parvocellular pathway may have significant input to the motion pathway, perhaps at the level of MT. Whether the effect we report here has close relation- 
ship to the well-known Benham's top (1894) and Bidwell's ghost (1896)-wherein colors are seen when black and white stimuli are shown in quick temporal succession-is left unanswered by these results. However, our results suggest the possibility of a more central site for the locus of these effects, rather than the conventional cone-based explanation.

Our discussion focuses on using dynamic color spreading to understand the neurophysiology underlying the perception of color and motion. We leave unanswered the question of whether dynamic color spreading is merely an artifact of the neural wiring or whether it may have an adaptive function. Given that dynamic color spreading involves luminance contrast and transparency, elements known to be important for image segmentation, one cannot rule out the possibility that it may have an adaptive function. In this case, there should be a computational theory (Marr, 1982) for dynamic color spreading. Such a theory would likely build upon existing computational theories for the perception of luminance changes (e.g., Ullman, 1976; Witkin, 1982) and the perception of transparency (e.g., Metelli, 1974, 1985).

\section{REFERENCES}

Allman, J., Miezin, F., \& McGuinness, E. (1985). Direction- and velocity-specific responses from beyond the classical receptive field in the middle temporal visual area (MT). Perception, 14, 105-126.

Benham, C. E. (1894). The artificial spectrum top. Nature, 51, 200.

BIDWELL, S. (1896). On subjective colour phenomena attending sudden changes in illumination. Proceedings of the Royal Society, 60, 368377.

BRESSAN, P. (1993). Revisitation of the luminance conditions for the occurrence of the achromatic neon color spreading illusion. Perception \& Psychophysics, 54, 55-64.

Bressan, P., \& Vallortigara, G. (1991). Illusory depth from moving subjective figures and neon colour spreading. Perception, 20, 637644.

Cavanagh, P., Bogglin, J., \& Favreau, O. E. (1985). Perception of motion in equiluminous kinematograms. Perception, 14, 151-162.

Cortese, J. M., \& ANDERSEN, G. J. (1991). Recovery of 3-D shape from deforming contours. Perception \& Psychophysics, 49, 315-327.

Croner, L., \& KAPLAN, E. (1995). Receptive fields of P and M ganglion cells across the primate retina. Vision Research, 35, 7-24.

Crook, J. M., Lange-Malecki, B., Lee, B. B., \& VAlberg, A. (1988). Visual resolution of macaque retinal ganglion cells. Journal of Physiology, 396, 205-224.

DAY, R. H. (1983). Neon color spreading, partially delineated borders, and the formation of illusory contours. Perception \& Psychophysics, 34, 488-490.

DeMonasterio, F. M., \& Gouras, P. (1975). Functional properties of ganglion cells of the rhesus monkey retina. Journal of Physiology, 251, 167-195.

DeMonasterio, F. M., \& Schein, S. J. (1982). Spectral bandwidths of color-opponent cells of geniculocortical pathway of macaque monkey. Journal of Neurophysiology, 47, 214-224.

DeYoe, E. A., \& VAN EsSEn, D. C. (1985). Segregation of efferent connections and receptive field properties in visual area V2 of the macaque. Nature, 317, 58-61

Dobkins, K. R., \& ALbRight, T. D. (1993). What happens if it changes color when it moves? I. Psychophysical experiments on the nature of chromatic input to motion detectors. Vision Research, 33, 10191036.

DUBNER, R., \& ZEKI, S. M. (1971). Response properties and receptive fields of cells in an anatomically defined region of the superior temporal sulcus in the monkey. Brain Research, 35, 528-532.

Ehrenstein, W. (1941). Über Abwandlungen der L. Hermannschen
Helligkeitserscheinung. Zeitschrift für Psychologie, 150, 83-91. [Modifications of the brightness phenomenon of L. Hermann (Anne Hogg, Trans.). In S. Petry \& G. E. Meyer (Eds.) (1987). The perception of illusory contours (pp. 35-39). New York: Springer-Verlag.]

Fujita, N. (1993). An occluded contour becomes visible with reversal of disparity. Perceptual \& Motor Skills, 77, 271-274.

GREGORY, R. L. (1977). Vision with isoluminant colour contrast: 1. A projection technique and observations. Perception, 6, 113-119.

HUBEL, D. H., \& WiESEL, T. N. (1960). Receptive fields of optic nerve fibres in the spider monkey. Journal of Physiology, 154, 572-580.

Kellman, P. J., \& Cohen, M. H. (1984). Kinetic subjective contours. Perception \& Psychophysics, 35, 237-244.

Kersten, D., BülthofF, H. H., Schwartz, B. L., \& Kurtz, K. J. (1992). Interaction between transparency and structure from motion. Neural Computation, 4, 573-589.

Klymenko, V., \& WeIsSTEIN, N. (1981). The motion-induced contour. Perception, 10, 627-636.

KooI, F. L., DeValois, K. K., Switkes, E., \& Grosof, D. H. (1992). Higher order factors influencing the perceived motion of plaids. Perception, 21, 583-598.

KRAUSKOPF, J., \& FARELL, B. (1990). Influence of color on the perception of coherent motion. Nature, 348, 328-331.

LAPPIN, J. S., Doner, J. F., \& KotTas, B. (1980, August 8). Minimal conditions for the visual detection of structure and motion in three dimensions. Science, 209, 717-719.

Lennie, P., Trevarthen, C., Van Essen, D., \& Wassle, H. (1990). Parallel processing of visual information. In L. Spillmann \& J. S. Werner (Eds.), Visual perception (pp. 103-128). San Diego, CA: Academic Press.

Livingstone, M., \& Hubel, D. (1988, May 6). Segregation of form, color, movement and depth: Anatomy, physiology and perception. Science, 240, 740-750.

MARR, D. (1982). Vision. San Francisco: W. H. Freeman

Metelli, F. (1974). The perception of transparency. Scientific American, 230, 90-98.

Metelli, F. (1985). Stimulation and perception of transparency. Psychological Research, 47, 185-202.

Mikami, A., Newsome, W. T., \& Wurtz, R. H. (1986). Motion selectivity in macaque visual cortex: II. Spatiotemporal range of directional interactions in MT and V1. Journal of Neurophysiology, 55, 1328-1339.

Movshon, J. A., Adelson, E. H., Gizzi, M. S., \& Newsome, W. T. (1986). The analysis of moving patterns. In C. R. Chagas \& C. Gross (Eds.), Pattern recognition mechanisms (pp. 117-151). Berlin: SpringerVerlag.

NAKAYAMA, K., \& ShImojo, S. (1990). Toward a neural understanding of visual surface representation. The brain: Cold Spring Harbor Symposia on Quantitative Biology, 55, 911-924.

Nakayama, K., Shimojo, S., \& Ramachandran, V. S. (1990). Transparency - relation to depth, subjective contours, luminance, and neon color spreading. Perception, 19, 497-513.

Newsome, W. T., \& PARE, E. B. (1988). A selective impairment of motion processing following lesions of the middle temporal visual area (MT). Journal of Neuroscience, $\mathbf{8}, 2201-2211$.

Newsome, W. T., Wurtz, R. H., Dursteler, M. R., \& Mikami, A. (1985). Deficits in visual motion processing following ibotenic acid lesions of the middle temporal visual area of the macaque monkey. Journal of Neuroscience, 5, 825-840.

Peterhans, E., \& von DER HeYdT, R. (1991). Subjective contoursbridging the gap between psychophysics and physiology. Trends in Neurosciences, 14, 112-119.

RAMACHANDRAN, V. S. (1986). Capture of stereopsis and apparent motion by illusory contours. Perception \& Psychophysics, 39, 361-373.

RamachandRan, V. S., \& GREGoRY, R. L. (1978). Does colour provide an input to human motion perception? Nature, 275, 55.

REDIES, C., \& SPILlMANN, L. (1981). The neon color effect in the Ehrenstein illusion. Perception, 10, 667-681.

Sekuler, R., \& Levinson, E. (1977, January). The perception of moving targets. Scientific American, 236, 60-73.

SHAPLEY, R., \& PERRY, V. H. (1986). Cat and monkey retinal ganglion cells and their visual functional roles. Trends in Neurosciences, 9, 229-235.

SHIPP, S., \& ZEKI, S. (1985). Segregation of pathways leading from area 
$\mathrm{V} 2$ to areas $\mathrm{V} 4$ and $\mathrm{V} 5$ of macaque monkey visual cortex. Nature, 315. 322-324

Stoner. G. R., \& Albricht, T. D. (1993). Image segmentation cues in motion processing: Implications for modularity in vision. Journal of Cognitive Neuroscience, 5, 129-149.

Takeichi, H., Shimojo, S., \& Watanabe, T. (1992). Neon flank and illusory contour-interaction between the two processes leads to color filling-in. Perception, 21, 313-324.

Tanaka, K., Hikosaka, H., Saito, H., Yukie, Y., Fukuda, Y., \& IWAI, E. (1986). Analysis of local and wide-field movements in the superior temporal visual areas of the macaque monkey. Journal of Neuroscience, 6, 134-144.

TREISMAN, A. (1982). Perceptual grouping and attention in visual search for features and for objects. Journal of Experimental Psychology: Human Perception \& Performance, 8, 194-214.

Trueswell, J. C., \& Hayhoe, M. M. (1993). Surface segmentation mechanisms and motion perception. Vision Research, 33, 313-328.

Ullman, S. (1976). On visual detection of light sources. Biological $C y$ bernetics, 21, 205-212.

Ullman, S. (1979). The interpretation of visual motion. Cambridge, MA: MIT Press.
VAN Tuisl, H. F. J. M. (1975). A new visual illusion: Neonlike color spreading and complementary color induction between subjective contours. Acta Psychologica, 39, 441-445.

VARIN, D. (1971). Fenomeni di contrasto e diffusione cromatica nell'organizzazione spaziale del campo percettivo. Rivista di Psicologia, 65, $101-128$.

Wallach, H., \& O'Connell, D. N. (1953). The kinetic depth effect. Journal of Experimental Psychology, 45, 205-217.

Watanabe, T., \& SaTO, T. (1989). Effects of luminance contrast on color spreading and illusory contour in the neon color spreading effect. Perception \& Psychophysics, 45, 427-430.

Watanabe, T., \& Takeichi, H. (1990). The relation between color spreading and illusory contours. Perception \& Psychophysics, 47, 457-467.

Witkin, A. P. (1982). Intensity-based edge classification. Proceedings of the Fifth National Conference on Artificial Intelligence (pp. 36-41). Palo Alto, CA: AAAI.

WYSZECKI, G., \& STILES, W. S. (1982). Color science. NeW York: Wiley.

Yamada, W., Fujita, N., \& Masuda, N. (1993). Amodal completion as another perception of color-spreading stimuli. Perceptual \& Motor Skills, 76, 1027-1033.

\section{APPENDIX A}

The stimuli for Experiments 1-5 were generated using Mathematica on a Macintosh. Below is a Mathematica program which generates stimuli of the type used in Experiments 1 and 2. Simple modifications of this program were used to generate stimuli for the other experiments. Following the Mathematica program is a single command which invokes the program and generates a display consisting of 12 frames with 900 dots in each frame.

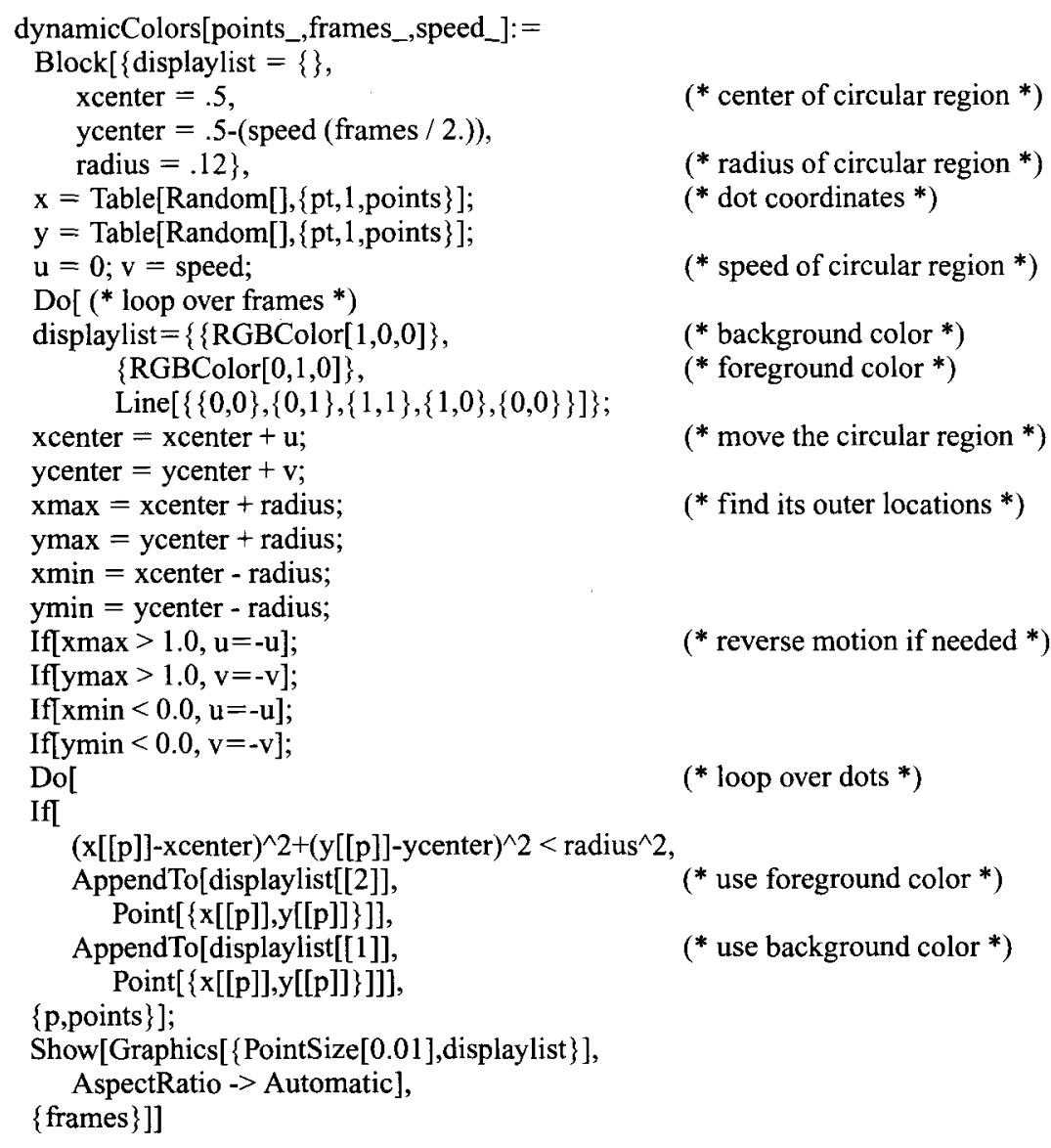

This program can be used to generate a sequence of 12 frames with 900 dots per frame by typing the following command:

dynamicColors $[900,12,0.025]$ 


\section{APPENDIX B}

Appendix B contains three tables of measurements from Experiments 3 and 4. Table B1 contains the color matches made to the gray dots in the static condition (plotted in Figures 6 and 7). Table B2 contains color matches to the gray dots under conditions of apparent motion (plotted in Figures 8 and 9). Table B3 contains color matches to dynamic color spreading under conditions of apparent motion (plotted in Figures 10 and 11).

Table B1

Static Dots

\begin{tabular}{|c|c|c|c|c|c|c|c|c|c|c|c|c|}
\hline \multirow[b]{3}{*}{ Luminance } & \multicolumn{12}{|c|}{ Observer } \\
\hline & \multicolumn{2}{|c|}{ G.B. } & \multicolumn{2}{|c|}{ C.C. } & \multicolumn{2}{|c|}{ P.G. } & \multicolumn{2}{|c|}{ D.H. } & \multicolumn{2}{|c|}{ J.K. } & \multicolumn{2}{|c|}{ J.L. } \\
\hline & $x$ & $y$ & $x$ & $y$ & $x$ & $y$ & $x$ & $y$ & $x$ & $y$ & $x$ & $y$ \\
\hline 15.3 & 0.251 & 0.294 & 0.281 & 0.302 & 0.241 & 0.272 & 0.283 & 0.303 & 0.274 & 0.296 & 0.268 & 0.290 \\
\hline 23.4 & 0.241 & 0.291 & 0.283 & 0.302 & 0.232 & 0.267 & 0.280 & 0.303 & 0.269 & 0.295 & 0.270 & 0.296 \\
\hline 32.3 & 0.269 & 0.300 & 0.282 & 0.301 & 0.261 & 0.296 & 0.280 & 0.304 & 0.276 & 0.298 & 0.274 & 0.297 \\
\hline 42.5 & 0.274 & 0.300 & 0.282 & 0.303 & 0.271 & 0.301 & 0.279 & 0.303 & 0.279 & 0.300 & 0.277 & 0.301 \\
\hline 53.0 & 0.276 & 0.300 & 0.281 & 0.302 & 0.271 & 0.299 & 0.283 & 0.304 & 0.278 & 0.300 & 0.278 & 0.302 \\
\hline
\end{tabular}

Note-Luminance is given in $\mathrm{cd} / \mathrm{m}^{2} ; x$ and $y$ are CIE coordinates.

Table B2

Motion Dots

\begin{tabular}{|c|c|c|c|c|c|c|c|c|c|c|c|c|}
\hline \multirow[b]{3}{*}{ Luminance } & \multicolumn{12}{|c|}{ Observer } \\
\hline & \multicolumn{2}{|c|}{ G.B. } & \multicolumn{2}{|c|}{ C.C. } & \multicolumn{2}{|c|}{ P.G. } & \multicolumn{2}{|c|}{ D.H. } & \multicolumn{2}{|c|}{ J.K. } & \multicolumn{2}{|c|}{ J.L. } \\
\hline & $x$ & $y$ & $x$ & $y$ & $x$ & $y$ & $x$ & $y$ & $x$ & $y$ & $x$ & $y$ \\
\hline 15.3 & 0.223 & 0.298 & 0.231 & 0.294 & 0.218 & 0.258 & 0.228 & 0.279 & 0.250 & 0.290 & 0.264 & 0.290 \\
\hline 23.4 & 0.233 & 0.284 & 0.233 & 0.292 & 0.224 & 0.264 & 0.232 & 0.288 & 0.241 & 0.293 & 0.266 & 0.292 \\
\hline 32.3 & 0.265 & 0.297 & 0.246 & 0.296 & 0.252 & 0.291 & 0.247 & 0.292 & 0.259 & 0.297 & 0.272 & 0.298 \\
\hline 42.5 & 0.264 & 0.297 & 0.283 & 0.303 & 0.271 & 0.301 & 0.283 & 0.303 & 0.270 & 0.299 & 0.278 & 0.303 \\
\hline 53.0 & 0.274 & 0.299 & 0.283 & 0.303 & 0.274 & 0.302 & 0.283 & 0.303 & 0.273 & 0.299 & 0.280 & 0.304 \\
\hline
\end{tabular}

Note-Luminance is given in $\mathrm{cd} / \mathrm{m}^{2} ; x$ and $y$ are CIE coordinates.

Table B3

Color Spreading

\begin{tabular}{|c|c|c|c|c|c|c|c|c|c|c|c|c|}
\hline \multirow[b]{3}{*}{ Luminance } & \multicolumn{12}{|c|}{ Observer } \\
\hline & \multicolumn{2}{|c|}{ G.B. } & \multicolumn{2}{|c|}{ C.C. } & \multicolumn{2}{|c|}{ P.G. } & \multicolumn{2}{|c|}{ D.H. } & \multicolumn{2}{|c|}{ J.K. } & \multicolumn{2}{|c|}{ J.L. } \\
\hline & $x$ & $y$ & $x$ & $y$ & $x$ & $y$ & $x$ & $y$ & $x$ & $y$ & $x$ & $y$ \\
\hline 15.3 & & & 0.283 & 0.303 & 0.279 & 0.300 & 0.283 & 0.303 & 0.280 & 0.299 & & \\
\hline 23.4 & & & 0.283 & 0.303 & 0.277 & 0.300 & 0.283 & 0.303 & 0.280 & 0.301 & & \\
\hline 32.3 & 0.280 & 0.301 & 0.275 & 0.302 & 0.277 & 0.300 & 0.280 & 0.302 & 0.280 & 0.302 & 0.281 & 0.302 \\
\hline 42.5 & 0.278 & 0.300 & 0.282 & 0.303 & 0.210 & 0.301 & 0.276 & 0.304 & & & 0.282 & 0.304 \\
\hline 53.0 & 0.280 & 0.302 & 0.281 & 0.303 & & & 0.281 & 0.304 & & & 0.284 & 0.306 \\
\hline
\end{tabular}

Note-Luminance is given in $\mathrm{cd} / \mathrm{m}^{2} ; x$ and $y$ are CIE coordinates.

(Manuscript received August 15, 1994;

revision accepted for publication February 8, 1995.) 